Lexis Vol. XLIV (1) 2020: 5-39

\title{
No más, nada más: formación de adverbios de exclusión ('solamente’)*
}

\author{
Francisco Javier Herrero Ruiz de Loizaga \\ Instituto Universitario Menéndez Pidal \\ Universidad Complutense de Madrid
}

\section{RESUMEN}

Estudiamos, en este trabajo, el desarrollo de los valores adverbiales del tipo 'solamente' de no más y nada más. Partimos de los datos proporcionados por los corpus de la Real Academia, y tenemos también en cuenta el Corpus del Español (CE) de Davies y PRESEEA. La aparición de no más con el valor de 'solamente' se observa desde los primeros textos castellanos, probablemente por reducción de la secuencia y no más, pospuesta al elemento sobre el que incide. Esta construcción, gramaticalizada como marcador de foco, es frecuente en el español medieval y en los Siglos de Oro. A partir del siglo XVIII, también se documenta nada más con ese valor y su empleo crece en el español peninsular moderno, que va abandonando el uso de no más. En cambio, la forma no más se mantuvo en toda Hispanoamérica, en donde desarrolla nuevos valores.

Palabras clave: adverbio de foco, exclusión, gramaticalización

\footnotetext{
* Este trabajo se inserta en el marco del proyecto FFI2015-64080-P Procesos de gramaticalización en la historia del español (V): gramaticalización, lexicalización y análisis del discurso desde una perspectiva histórica, del Ministerio de Economía y Competitividad.
}

https://doi.org/10.18800/lexis.202001.001 
No más, nada más. Formation of Adverbs of Exclusion ('only')

ABSTRACT

We study in this paper the development of the adverbial value 'only' of no más y nada más. We start from the data provided by the corpora of the Real Academia and we take also into account the Davies' Corpus del Español (CE) and PRESEEA. The appearance of no más with the value of 'only' occurs from the first Castilian texts, probably due to a reduction in the sequence $y$ no más postponed to the element on which it focuses. This construction, grammaticalized into a focus marker, is frequent in medieval Spanish and in the Golden Age. Since the 18th century, nada más is documented with the value 'solamente', and its use grows in European Spanish, while no más falls in disuse. Instead, the form no más remained throughout Latin America, where it develops new values.

Keywords: Focus adverb, exclusion, grammaticalization

\section{Introducción}

Las expresiones no más o nomás, presentada gráficamente como un solo signo, y nada más funcionan en el español actual como adverbios de foco que señalan exclusión con el valor de 'solamente': "No estás obligado a hacerlo, es un consejo nomás/nada más”.

La forma no más (o nomás) es sentida, hoy en día, como peculiarmente hispanoamericana. Así podemos verlo en el título del conocido trabajo de Kany (1945), “American Spanish no más”, que comienza con las siguientes palabras: "The adverbial locution no más, with its manifold connotations, is characteristic of American Spanish" (Kany 1945: 72). La Nueva gramática de la lengua espanola (NGLE) afirma, también, casi con las mismas palabras, que “[e]l adverbio no más (o nomás) es característico del español americano" (2009: 3015).

Sin embargo, no más o nomás no es un adverbio de exclusión que se haya creado en el español de América. Su empleo como adverbio de exclusión con el valor de 'solamente’ es frecuente en el español clásico y se halla desde la época medieval. Más reciente es la forma nada 
más, que comienza a documentarse en el siglo XVIII. A partir de ese momento, entra en competencia con no más/ nomás, lo que dará lugar a dos procesos distintos: en el uso de España, el crecimiento de nada más va acompañado de un retroceso del uso de no más, que podemos considerar prácticamente desaparecido en esa función; en el español hispanoamericano, por el contrario, aunque también se ha introducido la nueva forma nada más, no más/nomás se ha mantenido con total vitalidad e, incluso, ha desarrollado nuevos empleos desconocidos, o al menos no documentados, en el español clásico.

\section{No más en el español medieval}

Weigert (1907: 185-186) llamó la atención sobre el uso de no más en Cervantes con el valor de 'solamente' pospuesto a un sustantivo o pronombre en construcciones de este tipo: "Dos cosas nomás”, “al primero le preguntó que por qué pecados iba de tan mala guisa. Él le respondió que por enamorado iba de aquella manera. — ¿Por eso no más? replicó don Quijote”. Señaló que, con menor frecuencia, se encuentra y no más: "Salga la hermosa Argüello Moza, una vez y no más”, e indicó la correspondencia con el francés antiguo et non mais. Melander (1920) retoma el estudio de Weigert y señala que no más aparece tras la palabra a la que se refiere y dentro de una frase afirmativa y aporta nuevos testimonios clásicos y modernos (Galdós y Echegaray). Especialmente, se fija en la construcción y no más, en la que la conjunción y precede a no más, así como también nota el paralelismo con la antigua construcción francesa et non mais, siempre precedida de conjunción, como la moderna et non plus que la reemplaza. Este autor se plantea cuál de las dos construcciones, no más o y no más, es la originaria (Melander 1920: 81) y llega a la conclusión, tras el análisis de los datos medievales, de que la construcción más antigua es y no más, que es la única que encuentra, junto con la forma enfática que no más, en los textos medievales: "Reynó después un Rey, Egyca fue llamado/ Dos annos, que non mas, vysquió en el rreynado" (Fernán González, 34a, citado en Melander 1920: 81), "Come el día de sábado las fabas et non mas" 
(Juan Ruiz, 1143a, citado en Melander 1920: 81). Señala, también, que, una vez que la expresión y no más se ha fijado por su frecuente uso, la conjunción $y$ llegaría a considerarse como superflua y pudo caer (Melander 1920: 82).

La explicación de Melander parece convincente y, desde luego, no puede resultar sorprendente que esta secuencia y no más presente un valor focalizador de exclusión. A fin de cuentas, ya desde el latín tardío se utilizó una construcción comparativa con el adverbio MAGIS precedido de negación para marcar la excepción (Richter 1908: 659; Bourciez 1946: 120, 272). Diversos autores (Llorens 1929: 156; Iglesias 2014: 2552-2557; Bourciez 1946: 272) comentan que el clásico NISI, en sus usos exceptivos, fue sustituido en el latín tardío por la locución SI NON, con la que compartía, en principio, usos condicionales. Bourciez señala que SI NON deja descendencia en los diversos romances, excepto en oriente: lat. Non babeo nisi unum fratrem daría lugar a non habeo si non unum fratrem, de donde, a su vez, provienen el it. non bo se non un fratello, esp. no tengo sino un hermano, ptg. não tenho senão um irmão y a. fr. je n'ai se un frere non. Asimismo, también se empleó en el latín tardío para señalar la excepción NON MAGIS1. Una construcción del tipo Non habeo magis quam unum fratrem daría lugar a construcciones del tipo it. non bo mai che un fratello, esp. no tengo más que un hermano, a fr. je n'ai mais qu'un frere, con el valor exclusivo de 'solo tengo un hermano'2. Ambas construcciones fueron frecuentes en español. En el español moderno, la construcción del tipo no más... que tiende a generalizarse, aunque con diferencias dialectales en la vitalidad de

\footnotetext{
1 Moignet (1973: 24-32) estudia el paso de una construcción comparativa negativa a la idea de excepción. Se centra en el caso del francés antiguo mais que, teniendo en cuenta los precedentes latinos y las formaciones paralelas en otros romances.

2 Una construcción exceptiva en correlación con un término negativo que le precede (no, nada, nadie... excepto) adquiere un valor exclusivo del tipo 'solamente'. En el español medieval y clásico fue, no obstante, más frecuente la construcción del tipo no tengo más de un hermano, tanto con la idea de límite como en las construcciones de foco de exclusión, que proceden de la sustitución del ablativo por $d e+\mathrm{SN}$ en construcciones del tipo plus (magis) o minus seguidos de numerales: plus triginta annis (Bassols 1981: 98) 'más de treinta años'.
} 
la construcción con sino (Herrero 2005: 77-78). Del mismo modo, es fácil suponer que la construcción comparativa pudo añadirse detrás de un elemento ya mencionado y unido a la oración anterior mediante una conjunción copulativa: Habeo unum fratrem et non magis. En este caso, lógicamente, se produciría la elipsis del verbo y del segundo término de la construcción comparativa, por ser los mismos de la oración precedente. De este modo, la secuencia et non magis, fuertemente fijada, se convertiría en fórmula focalizadora de un elemento precedente, generalmente un sustantivo o elemento en función sustantiva, y de ahí tendríamos las fórmulas del francés antiguo et non mais; del castellano e/y no más; y del catalán eli no més ${ }^{3}$. Una vez que se ha producido la gramaticalización como adverbio focalizador de exclusión, puede perderse, como sugería Melander, la conjunción que precede a NON MAGIS > no más 4 . Por su propio proceso de formación, y no más sigue al elemento sobre el que incide y se encuentra en una frase afirmativa, pues la negación que precede a más correspondería a la segunda oración en la que se ha producido la elipsis. Estas mismas características, en cuanto a posición y carácter afirmativo de la oración en la que aparece, se mantienen en la forma reducida no más 5 .

En cuanto a la documentación, encontramos e/y no(n) más desde los primeros textos castellanos e, incluso, en textos peninsulares escritos todavía en latín se encuentra et non magis. El más antiguo que localizamos procede de un documento cuyo original es del siglo IX, pero a través de una copia, probablemente, del siglo XII:

\footnotetext{
3 En el Corpus Informatitzat del Català Antic (CICA) pueden verse ejemplos de e/i no més desde el siglo XIII.

4 También, només, en catalán, responde a este proceso de formación y, probablemente, del mismo modo, el rumano numai (Găzdaru 1949). Sobre la elisión en procesos de gramaticalización en la formación de locuciones conjuntivas y marcadores discursivos, véase Herrero (2016).

5 También, pudo influir en la aparición de no más incidiendo directamente sobre un elemento precedente la existencia de NON MAGIS > no más, añadido tras pausa. La ausencia de conjunción en estos casos pudo apoyar la consolidación de la variante no más. A su vez, la ausencia de pausa en y no más favorecería su eliminación en no más yuxtapuesto.
} 
(1) et si abstraxerit inde aliquid, illud solummodo quod abstraxerit, reddat in duplo, et non magis (Donación de Ordoño I a la iglesia de Oviedo, 857, Corpus Diacrónico del Español (CORDE)).

Y se encuentran algunos ejemplos más en textos del siglo XI. Hay que destacar, no obstante, que, aunque no sea la variante más frecuente, la forma non más, no precedida de conjunción copulativa, es mucho más antigua de lo que suponían Melander (1920: 81-82), que no la considera forma medieval ${ }^{6}$, y Găzdaru (1949: 27-28), quien cree que su aparición "no parece ser posterior a los fines del siglo XV”. La posibilidad de utilizar corpus digitalizados permite, lógicamente, tener acceso a un repertorio de ejemplos mucho más amplio que el que podían manejar estos estudiosos. García Pérez (2013: 340) señala ya un ejemplo de la segunda mitad del siglo XIII:

(2) E cuenta maestre Pedro, e assí es, que esta lumbrera era en la tienda ó el candelero que vos dixiemos que fuera puesto en la cámara de los sacrificios después de la entrada de la tienda, e de noche ardién ý VII lámpadas, e de día cuatro non más, e que eran las mechas de yuncos (Alfonso X, General Estoria, c. 1275, Ed., Pedro Prieto Sánchez-Borja, citado en García Pérez 2013: 340).

$\mathrm{Y}$, en el CORDE, se encuentra algún ejemplo algo anterior, de mediados del XIII':

(3) tomen de la carne e remógenla en el uino, e úntenla con de la miel e déngela, e céuenlas d'esta manera fasta que sean sanas. $\mathrm{E}$ si ouieren la flaqueza en las alas no más, e ge lo uieren quando uolaren, que uuelan flacamientre e uieren que non se sacuden mucho e que non saltan aýna en las manos, mégenles sobre las alas (Abraham de Toledo, Moamín. Libro de los animales que cazan, 1250, CORDE).

\footnotetext{
6 El ejemplo más antiguo que este investigador halla procede del manuscrito $\mathrm{M}$ de la Crónica de 1344, copiado a finales del XV o principios del XVI.

7 He comprobado la exactitud de la lectura en el facsímil digitalizado en la Biblioteca Digital Hispánica (BDH), véase http://bdh-rd.bne.es/viewer.vm?id=0000151354\&page $=1$ [Consultado el 30 de mayo de 2020].
} 
E, incluso, en el fuero latino de Villavicencio, de finales del siglo XI, ya aparece una vez non magis no precedido de conjunción:

(4) Unusquisque in propria domo, quem voluerit Dominum habeat, et seniori, et de solare, in quo habitat donet pro suo foro decem panes, et media Kanatellam de vino, et una quarta de carnero, aut duos lumbos non magis, nisi sua sponte (Fueros de Villavicencio, c. 1090, CORDE).

Es, de todas formas, variante poco frecuente a lo largo de la Edad Media. El CORDE ofrece 271 ejemplos para la secuencia no(n) $m^{\prime} s^{8}$ en el siglo XIV, de las que, descartando las que corresponden a otras construcciones, 204 corresponden a $e, e t, y, \mathcal{E}$ no(n) más; y solo 11 , a no más con el valor de 'solamente'.

\section{No más en el español clásico}

Esta situación no cambia mucho a lo largo de los siglos XV y XVI, aunque ya en las últimas décadas del XVI hay cierto aumento del uso de no más 'solamente' no precedido de conjunción, lo cual se hace más intenso desde las primeras décadas del siglo XVII. Como consecuencia de su origen, la posición de no más es pospuesta e incide, básicamente, sobre sustantivos, no necesariamente cuantificados; sobre pronombres personales; $y$, sobre todo, demostrativos:

(5) Repararlas pretendía,/ si se pueden reparar/ cuchilladas tan mortales,/ con una aguja no más (Luis de Góngora y Argote, Romances, 1580-1627, CORDE);

(6) Marcela ¿Quién es?/ Riselo Yo./ Marcela ¿Yo no más? igrande palabra! (Lope de Vega, El acero de Madrid, c. 1608-1612, CORDE);

\footnotetext{
8 Hemos buscado, para el período 1301-1400, las cadenas no más, no mas, non más y non mas (la más frecuente).
} 
(7) Reina. Hágale el cielo en imitaros diestro,/ que con esto no más que le conceda,/ le ha dado todo el bien que le deseo (Lope de Vega, Peribánez y el comendador de Ocaña, c. 1610, CORDE).

Y, de ahí, se extiende su uso junto a algunos adverbios pronominales, infinitivos u otro elemento funcionalmente equivalente a un sustantivo, como una oración subordinada encabezada por cuanto o lo que, en las que hay implícita una idea de cantidad, de lo que hallamos algún ejemplo ya desde el siglo XV:

(8) [P]lega a los dioses que lo digáis de verdad, que seréis obidientes, y que no sea aquí no más (Relación de las cerimonias y rictos y población y gobernación de los indios de la provincia de Mechuacán, c. 1541, CORDE).

(9) [T]oda la ciencia de los chinas, viene a parar en saber escrebir y leer no más (José de Acosta, Historia natural y moral de las Indias, 1590, CORDE).

(10) [A]lgund tienpo sus anteçesores e ellas sus caseros e moradores de los dichos logares avian andado e usado paçer en los dichos terminos con sus ganados que abia sydo y hera dando liçençia e abtoridad los vezinos e moradores de las dichas aldeas de Narbaxa e Axpuru e quanto a ellas les pluguyesen no mas (Licencia de paso [Documentación del Archivo municipal de Salvatierra], 1438, CORDE).

Sin embargo, no siempre es fácil saber si todavía hay una pausa entre la oración subordinada y no más. De hecho, en casos semejantes, hay editores que introducen una coma:

(11) Fr. Gregorio dirá lo que hay que decir, no más (Santa Teresa de Jesús (Teresa de Cepeda y Ahumada), Carta a la M. María de S. José, priora de Sevilla. Malagón, 18 de junio de 1576 [Epistolario], CORDE).

En alguna ocasión, no más puede aparecer detrás de un verbo conjugado, no directamente detrás del elemento al que focaliza. Esto es perfectamente posible a partir de una secuencia con y no más con elisión de la conjunción copulativa: "le dio tres libros (y) 
no más”, “tres libros le dio (y) no más”. De este modo, podemos encontrar algunos ejemplos del tipo:

(12) y quando sencoge adelante y atrás es thetano dicho y es spasmo perfecto mas si aza vna parte sencoge no mas spasmo se llama (Francisco López de Villalobos, Sumario de la medicina con un compendio sobre las pestíferas bubas. Madrid, BN I1169, 1480, CORDE).

(13) ¿Cupido dizes no más? (Juan del Encina, Égloga de Cristino y Febea, c. 1509, CORDE).

(14) Justino.-¿¿Fasta dó llevas camino?/ Cristino.- Fasta aquí vengo no más (Juan del Encina, Égloga de Cristino y Febea, c. 1509, CORDE).

Dado que no más focaliza, generalmente, al segmento que le precede, en estos casos puede entenderse que focalice a toda la oración precedente ${ }^{9}$, compuesta por SN, Sprep. o adverbio + verbo, o, incluso, que focalice al verbo. De ahí que vayamos encontrando casos de no más 'solamente' pospuestos a un verbo que lleva un complemento también en forma oracional:

(15) Juan. [...] Quándo te resolverás/ a desposarte? Rosarda. A que acabe este negocio que es grave,/ quiero que aguardes no más (Lope de Vega, El alcalde mayor, c. 1609-1612, CORDE).

Incluso, pospuesto no más al verbo, sea en forma personal o no personal, puede aparecer, tras él, el complemento o el sujeto. En estos casos, desde una perspectiva moderna, puede dar la impresión de que no más afecta exclusivamente al complemento que le sigue, pero realmente se sitúa detrás del verbo, focalizando al elemento precedente o, tal vez, a toda la oración:

(16) quiso el buen Jesús en sí çufrir para mitigar más a su Padre la ira que nos tenía y para encarescer no más el grande amor con

\footnotetext{
9 Del mismo modo que, con el orden inverso en el focalizador solo, en una oración como "se encoge solo hacia una parte", solo focaliza exclusivamente a bacia una parte, pero, en "Solo se encoge hacia una parte", podemos entender que solo focaliza a toda la oración que sigue.
} 
que nos amaba (Fray Antonio de Guevara, Epistolas familiares, 1521-1543, CORDE).

(17) Entremos agora en aquella vastísima tierra firme tocando no más su descripción y calidades (Fray Bartolomé de las Casas, Apologética historia sumaria, 1527-1550, CORDE).

(18) DON TORIBIO Mari-Nuño, mi señora,/ estando en este retrete,/ porque la dije no más/ que buenas noches tuviese, puso las manos en mí (Calderón de la Barca, Guárdate del agua mansa, 1649, CORDE).

(19) Decir que gocé no más/ lo que comí y bebí es claro (Luis Vélez de Guevara, Don Pedro Miago, 1614, CORDE).

(20) Bien puede hacer Amor lo que quisiere/ mas, ¿qué puede ya hacer que no haya hecho?,/ secreto está mi mal acá en el pecho,/ entiéndalo no más quien me entendiere (Francisco de Figueroa, Poesía, c. 1550-1600, CORDE).

(21) Godoy. A què à ese varrio de la Costanilla/ Me traeis à las seis de la mañana?/ Cosme. A que sepais no mas, quien es Iuan Rana (Moreto 1675: 235 ${ }^{10}$ ).

En este último ejemplo, en la edición del siglo XVII, vemos que aparece una coma detrás de no más, lo que parece indicar que se sentía como modificador del verbo o de toda la oración, no de la oración interrogativa que sigue. No obstante, esta interpretación no es segura, pues el uso de la coma en un texto del XVII podía ser simplemente marca que señala el comienzo de una oración, en este caso, la interrogativa indirecta ${ }^{11}$. Incluso, puede seguir a un verbo que no lleva complemento alguno, caso en el que no podemos dudar que la focalización de no más ya ocurre directamente sobre el elemento verbal.

\footnotetext{
10 Accesible en línea: https://books.google.es/books?id=VrhdAAAAcAAJ\&printsec= frontcover\&hl=es\&source $=$ gbs_ge_summary_r\&cad $=0 \# \mathrm{v}=$ onepage\&q\&f$=$ false $\quad[$ Consultado el 30 de mayo de 2020].

11 La Real Academia, en su Orthographía de 1741, señala que la coma se pone "lo primero, al fin de cada oracion: lo segundo, antes de todo relativo, ó conjunción” (Real Academia Española 1741: 263). Sobre la puntuación en esta época, véase Santiago (1998).
} 
(22) Acuerdóme de un lugar de Séneca, dice que hay unos ingenios que pican no más, y otros que penetran (Gabriel Bocángel, Rimas y prosas, 1627, CORDE).

Cuando no más afecta al verbo de una oración subordinada, vaya esta al final de toda la oración (23), o tras el verbo y seguido de otros complementos (véase antes 16), puede entenderse que afecta a toda la subordinada, caso que se da con alguna frecuencia en las oraciones finales:

(23) Dezilde que algunas vezes/ quiere hazer muy del galán,/ y me dize mil requiebros/ para tentarme no más (José de Valdivielso, El villano en su rincón. Acto sacramental [Doce actos sacramentales y dos comedias divinas], 1622, CORDE).

No se encuentra, en cambio, en esta época, no más como focalizador precediendo al elemento focalizado, ya sea en interior de oración, ya al comienzo de ella. En estos casos, lo que sí puede encontrarse es no más de/que, que responden a la original estructura comparativa ${ }^{12}$. Cuando nos encontramos en latín con una comparativa en la que hay una comparación numérica, el segundo término va en ablativo: MAGIS DUOBUS LIBRIS, y, con la sustitución del ablativo por de $+\mathrm{SN}$, encontraremos las construcciones del tipo más de dos libros (Romero Cambrón 1989: 183; Herrero 2005: 478) o, si está negada, no más de dos libros, lo que implica 'solamente dos libros'. A partir de aquí, se extiende el uso de la preposición de a otras estructuras, especialmente a aquellas en que el segundo término de la comparación está constituido por una oración en la que no hay una cuantificación numérica, pero sí una idea de límite cuantitativo o intensivo, y presentan forma de oración de relativo neutro, en casos como es más difícil de lo que parecía o come más

12 Las estructuras del tipo no más de, como estructura continua, fijada con el valor de 'solamente', comienzan a registrarse en el CORDE a partir del siglo XV. Por supuesto, hay construcciones comparativas negativas con indicación de cantidad desde los orígenes, pero sin que la negación preceda directamente a más de: “non fiz más de dos cortes” (Cid, 3128). Las estructuras del tipo no más que comienzan a aparecer en el CORDE a partir del siglo XVI. 
de lo que pensaba, y, en la lengua medieval y clásica - son construcciones poco frecuentes ya en la lengua moderna-, también con cuanto:

(24) Non me metades miedo — dixo el caballero— más de quanto yo me tengo (Zifar, citado en Herrero 2005: 479).

A partir del uso de no más de ante determinadas oraciones subordinadas en las que la estructura comparativa negada propicia la interpretación de 'solamente' (26), se extendió probablemente a otras. Es frecuente, por ejemplo, ante oraciones causales (28):

(25) E porque al rrey don Fernando se le avían hallegado grandes conpañas de cavalleros e hijosdalgo de las comunidades, de las çibdades, villas e lugares de los sus rreynos, e por grandes conbates que mandó dar a los de Córdoua, e por grandes * menguas de viandas, avnque les pesó, se le ovieron de dar, con que los asegurase las vidas e que saliesen no más de con los cuerpos (Pedro de Escavias, Repertorio de príncipes de España, 14671475, CORDE).

(26) “No es rrazón, mas ved lo que querés."

"Señor, no más de lo que mandardes." (La corónica de Adramón, c. 1492, CORDE).

(27) Visto esto, mandó cessar el Almirante la fiesta del tañer y bailar, y sacar sobre cubierta algunas ballestas, y tiralles con dos ballestas, no más de para assombrallos (Relación del Tercer Viaje de Colón [Textos y documentos completos de Cristóbal Colón], 1498, CORDE).

(28) Item, ¿no más de porque los españoles les dixesen que obedeciesen por señores a los reyes de Castilla -ya que tuvieran lengua para se lo decir y ellos lo entendieran- eran obligados a los creer y, por consiguiente, a se subjetar [sic] a los Reyes y a los obedecer, teniendo ellos sus naturales reyes? (Fray Bartolomé de las Casas, Historia de las Indias, c. 1527-1561, CORDE).

(29) [L]as maravillosas propriedades del agua son muchas: de algunas se pueden dar razones; $y$, de otras, no más que contar lo que passa (Pedro Mejía, Silva de varia lección, c. 1540-1550, CORDE). 
Teniendo en cuenta los usos de la época, en los que no más no seguido de de o que se pospone al elemento que focaliza, no creemos que sea correcta la lectura de algunos textos recogidos en CORDE:

(30) Rodancho. Por vida de la que tú sabes y, mía, que no lo emos de prouar tan solamente.

Pandulfo. No más beuerlo todo, que se saluará el juramento (Gaspar Gómez de Toledo, Tercera parte de la tragicomedia de Celestina, 1536, CORDE).

(31) Severo: ¿Habló la serpiente a Adán?

Dileto: Nomás fue el enemigo que habló en ella, así como muchas /19r vezes habla en hombres y mujeres que tienen espíritu (Jorge de Montemayor, Diálogo espiritual, 1543-1548, CORDE).

En estos casos, parece claro que la lectura adecuada sería "No, mas", adverbio de negación, seguido de conjunción adversativa (en este contexto, adversativa exclusiva).

\section{No más y nada más en el siglo XVIII}

En el siglo XVIII, todavía seguimos encontrando los usos anteriores. ${ }^{13}$

El uso de no más (no seguido de que, que ya va siendo más frecuente que no más de) antepuesto al elemento focalizado es todavía muy raro en el siglo XVIII. El CORDE recoge algunos ejemplos en el teatro de Ramón de la Cruz, donde se muestran rasgos del habla coloquial. Este uso refleja la total gramaticalización de no más, lo que permite el cambio de orden y está probablemente favorecido por la fijación de no más que como elemento focalizador, del que podría sentirse como variante formal:

\footnotetext{
13 En CORDE, se registra un ejemplo de no más focalizador antepuesto a una oración causal encabezada por porque: “[...] aquel le pintará mui bien, y este, mui mal. Y esto ¿por qué? No más porque aquel le vio mui bien, y este, mui mal (Benito Jerónimo Feijoo, Teatro Crítico Universal, 1734, CORDE)", pero se trata de una errata. En la edición de 1734 se lee No más que porque.
} 
(32) Paula. Mujer, déjame á mí dar/ la última mano, y te queda/ luego el espejo por tuyo./ Paca. Cuanto perfilo las cejas/ no más un poco (Ramón de la Cruz, El caballero de Medina, 1764, CORDE)

(33) Ayala. Si no hallo arbitrio ninguno./ Guzmana. Yo te diera uno [...]/ Ayala. Vamos, habla./ Guzmana. No más conque tú permitas/ venga de tertulia á casa/ don Alberto (Ramón de la Cruz, El chasco de los aderezos, 1765, CORDE).

En el siglo XVIII, también comenzamos a encontrar, junto a no más, la secuencia nada más. En principio, su creación es paralela a la de no más, como ya había señalado Melander (1920: 83), quien da ejemplos de ella desde el siglo XIX. Nada, reforzando a la construcción no... más de/que, comienza a documentarse en el CORDE en el siglo $\mathrm{XV}^{14}$, se hace algo más frecuente en el XVI y crece de un modo moderado en el XVII:

(34) E Ellos fueronse derecha mente ala puerta del castillo mas de dentro del hera muj escuro E grande E no podia ver ome nada mas de quanto veya En vna cueba de so tierra (Traduccción de Lanzarote del Lago, c. 1414, CORDE).

(35) Motezuma [...] con grande espanto e voces llamó a la gente de su guardia para que viesen lo que él había visto e vía, e venido no vieron nada más de a su señor extrañamente turbado (Francisco Cervantes de Salazar, Crónica de la Nueva España, 1560, CORDE).

(36) Solemos decir en Castellano: En qué entiende Fulano? No entiende en nada más que en esto (Fray Alonso de Cabrera, De

14 Espinosa (2014: 1015) señala el surgimiento de nada más de/que a partir de entornos negativos y da ejemplos a partir del XVI. García Pérez (2013: 341 y n.) dice que se usa esporádicamente en los siglos XIII y XIV. Señala en nota que encuentra un solo ejemplo de esta época, del Libro de Apolonio: “[...] mas, si me lo defiende poblado ni yermo,/ tenerme ýa por nada, más que vn seco ensierto” (Libro de Apolonio, c. 1240, Ed., Dolores Corbella), pero la interpretación no es clara. De hecho, Dolores Corbella introduce coma tras nada, lo que implica que no lo entiende como el adverbio de foco con construcción unitaria. Igual puntuación da Manuel Alvar (Barcelona, Planeta, 1939, p. 8) en esta copla 39 del Libro de Apolonio (en cambio, no hay coma en la edición de Monedero, Castalia, 1987, p. 108). Dado que no parece usarse nada más como adverbio de foco en esta época, creemos que no debe entenderse como un único elemento: nada sigue funcionando como pronombre indefinido, término de tener por; más que inicia una nueva oración comparativa con verbo elíptico. 
las consideraciones sobre todos los evangelios de la Cuaresma, 1598, CORDE).

No se registran en estos siglos casos de y nada más o nada más pospuestos al elemento focalizado. El CORDE recoge un ejemplo de cada una de estas estructuras:

(37) Ningún labrador que por su persona trabajare o hubiere trabajado, aunque ya labre con sus quinteros, no siendo hijosdalgo, puede traer en su vestido más de una sola vestidura de seda, como un jubón, o un sombrero y nada más (Lope de Deza, Gobierno político de agricultura, 1618, CORDE).

(38) Así le agregarán a la palabra escrita estas dos letras: es, diciéndole por escrito o con la mano que a los que acaban en a, e, o se añade la s nada más (Juan Pablo Bonet, Reducción de las letras y arte para enseñar a hablar los mudos, 1620, CORDE).

Sin embargo, en ambos casos, hay una modificación del texto original, en el que se leía no más ${ }^{15}$.

En el siglo XVIII, hay un considerable aumento del empleo de la secuencia nada más. De hecho, si comparamos el empleo de la secuencia nada más en el siglo XVIII y en los siglos anteriores en los textos recogidos en CORDE, observamos un notable incremento de su empleo, lo que, indudablemente, está en relación con su creciente fijación en determinadas secuencias en las que se aproxima al valor de 'solamente':

\footnotetext{
15 Puede comprobarse con el facsímil de los originales, publicados en línea en la $B D H$, véase http://bdh-rd.bne.es/viewer.vm?id=0000079359\&page=1 [Consultado el 30 de mayo de 2020], y la Biblioteca Virtual Miguel de Cervantes, véase http://www. cervantesvirtual.com/obra-visor/reduccion-de-las-letras-y-arte-para-ensenar-a-hablara-los-mudos--0/html/ff9182e0-82b1-11df-acc7-002185ce6064_229.htm [Consultado el 30 de mayo de 2020]. García Pérez (2013: 341-342), basándose en este ejemplo del $C O R D E$, piensa que ya en el XVII se produce el paso hacia la lexicalización-gramaticalización de nada más, pero, como hemos visto, no es una transcripción correcta y habrá que esperar al XVIII para hallar este tipo de ejemplos.
} 


\begin{tabular}{|c|c|c|c|}
\hline & $\begin{array}{l}\mathrm{N}^{\circ} \text { total de palabras } \\
\text { en CORDE }\end{array}$ & $\begin{array}{l}\text { Ocurrencias de la } \\
\text { secuencia nada más }\end{array}$ & $\begin{array}{l}\text { Ocurrencias por } \\
\text { millón de palabras }\end{array}$ \\
\hline Siglo XV & 22241671 & $4^{16}$ & 0,18 \\
\hline Siglo XVI & 50620521 & $31^{17}$ & 0,61 \\
\hline Siglo XVII & 36386678 & $38^{18}$ & 1,04 \\
\hline Siglo XVIII & 14490011 & $156^{19}$ & 10,77 \\
\hline
\end{tabular}

Aun siendo bajo el empleo de nada más en todos los períodos estudiados, vemos cómo se triplica la frecuencia del siglo XV al XVI, casi se duplica en el XVII respecto al XVI y es diez veces superior en el siglo XVIII que en el XVII.

Para el siglo XVIII, podemos observar, paralelamente a lo que sucedió con no más de, una disminución muy grande en el uso de nada más de, al tiempo que se va afianzando nada más que antepuesto. En el siglo XV, el CORDE ofrece un ejemplo de nada más de con el valor de 'solamente'; 17 en el siglo XVI; 11 en el XVII; y ya solo 2 en el XVIII, aunque en uno de ellos nos hallamos ante la estructura nada más de lo que, una de las estructuras comparativas de superioridad que se han mantenido en el español moderno, como vimos antes:

16 El CORDE recoge 3 ejemplos del siglo XV al pedirle que recupere no más con mayúscula y minúscula, a los que hay que sumar 1 caso más que recupera al pedirle no mas sin tilde (en el resto de los ejemplos, 40, mas es conjunción adversativa. En 1 caso, nada es verbo).

17 El CORDE recupera 29 ejemplos de nada más con mayúscula y minúscula en el siglo XVI. Hay que sumar 2 de los 41 que recupera al pedirle nada mas sin tilde.

18 El CORDE recupera 45 ejemplos de nada más con mayúscula y minúscula para el XVII. Hay que descontar 6 ejemplos que proceden del Suplemento al Tesoro de la lengua española castellana, que aparecen todos entre corchetes y corresponden a traducciones de los editores modernos (Georgina Dopico y Jacques Lezra, Covarrubias 2001) de citas hechas en latín por Covarrubias, y otros dos de Lope de Deza y Juan Pablo Bonet, que, como hemos visto, corresponden a modificaciones de la secuencia no más que se hallaba en el original. Habría que sumar 2 de los casos que se recuperan al pedir no mas sin tilde, pero 1 de ellos, de Luis Cabrera de Córdoba (c. 1599-1614), lo hemos contado con los del $\mathrm{XVI}$, ya que lo recupera en los dos siglos.

19 El CORDE recoge 157 ejemplos en 88 obras en el XVIII, pero uno fechado como 1777 procedente del Cartulario de las Universidades Hispánicas aparece en la entradilla al documento del XVIII, hecha por los editores modernos (C. María Ajo y Sainz de Zúñiga), en 1960. Los 3 últimos ejemplos, de las Poesías de Francisco Sánchez Barbero, c. 1800-1819, corresponden, probablemente, al siglo XIX, pero, aunque los eliminemos y reduzcamos los ejemplos del XVIII a 153, ello, prácticamente, no afecta las estadísticas. 
(39) Guzmana. Muchacha, ¿qué estás diciendo?/ Nicolasa. Nada más de que el señor/ No me gusta y es muy feo (Ramón de la Cruz, De tres, ninguna, 1771, CORDE).

(40) Nada más de lo que he referido hizo Tejeira, según consta de jurídicos/ documentos (Juan de Velasco, Historia del reino de Quito en la América Meridional, 1789, CORDE).

Se observa, también, un gran crecimiento de no... nada más que, nada más [...] que o (no)...nada más [...] sino que ${ }^{20}$, con doble fórmula de exclusión. Frente a 1 ejemplo en el siglo XVI y 4 en el XVII, el CORDE recoge 41 en el XVIII.

(41) Estos hombres no tienen nada más que sus brazos, y con ellos han de/ ganar su sustento (Pablo de Olavide, Informe al Consejo sobre la Ley Agraria, 1768, CORDE).

(42) essos grandes héroes que celebra con sus clarines la fama, nada más fueron que unos malhechores de alta guía más (Benito Jerónimo Feijoo, Teatro crítico universal, 1729, CORDE).

(43) y nada más desean sino que quieta y pacíficamente os conservéis á su dominación como en depósito para devolverlo todo, según que los Reyes español y británico convinieren y se concordaren (Manifiesto del Arzobispo a los naturales de Filipinas [Documentos indispensables para la verdadera historia de Filipinas], 1762, CORDE).

En los ejemplos anteriores, puede entenderse que nada presenta una función sintáctica dentro de la oración en la que se inserta, independientemente de que, desde el punto de vista pragmático comunicativo, presente el mismo valor que 'solamente'. Así, por ejemplo, en la primera (41) y en la tercera (43), funciona como complemento directo de tienen y desean respectivamente; en la segunda es atributo de fueron, pero, cuando aparece sin que podamos asignarle una función sintáctica en la oración, únicamente con el valor de 'solamente' focalizando al elemento sobre el que incide, es claro

20 En francés, se documenta con anterioridad el esquema rien plus, sinon que, que tal vez pudo influir en el uso de (no)...nada más [...] sino que en castellano, pero haría falta un estudio pormenorizado para poder comprobarlo. 
que se ha completado el proceso de gramaticalización. En estos casos, puede aparecer en un contexto en el que no hay un verbo negado, más allá de los contextos en que originariamente se había creado:

(44) Aquí prendió al Ministro, que es religioso de mi Provincia, le llevó preso á Lipa, en donde cogió á su Ministro, y á los dos remitió presos á Manila, nada más que por ser religiosos agustinos y por decir que éstos eran los que hacían guerra en la Pampanga y Bulacán (Fray José Victoria, Documento inédito [Documentos indispensables para la verdadera historia de Filipinas], c. 1773, CORDE).

Y comenzamos a encontrar los primeros ejemplos de y nada más, o nada más, tras pausa en principio (en los impresos de la época suele aparecer tras coma), con el valor de 'solamente', aunque no es fácil saber en muchos casos si había pausa o, si ya sin ella, funciona como auténtico adverbio de foco. Los primeros ejemplos que recoge el CORDE son de Feijoo:

(45) Pero, el philósofo ¿qué sabe? Dudar de todo y nada más (Benito Jerónimo Feijoo, Teatro crítico universal, 1729, CORDE).

(46) Las piedras preciosas en las oficinas de los boticarios sirven de lo mismo que en las joyas de las señoras, de adorno y ostentación, nada más (Benito Jerónimo Feijoo, Teatro crítico universal, 1739, CORDE).

(47) Decía que me quería/ por quererme nada más,/ sin interés ni codicia,/ que es mucho en un catalán (La peregrina viajante por España. Tonadilla a solo [Tonadillas teatrales inéditas], 1776, CORDE).

En la mayoría de los ejemplos en que encontramos y nada más y la forma todavía menos frecuente nada más, aparecen, de acuerdo con el contexto en que se crean, siguiendo a un sintagma nominal (sustantivo, pronombre o infinitivo) al que focalizan. La progresiva gramaticalización de esta secuencia hace que también, al menos desde la segunda mitad del siglo XVIII, empecemos a encontrarla focalizando a otros elementos, como un adjetivo o una oración: 
(48) [T]enía mi anteojo ynglés, y aun con este auxilio no descubría las cosas como yo quisiera, ni distinguía bien los árboles de las matas, ni de las viñas, todo me parecía verde y nada más (Conde de Fernán Núñez (Carlos Gutiérrez de los Ríos), Diario de la expedición contra Argel, 1775, CORDE).

(49) De tanto en tanto se veía que de la cumbre baxaban a la acción ya dos y ya quatro moros, nada más (Conde de Fernán Núñez (Carlos Gutiérrez de los Ríos), Diario de la expedición contra Argel, 1775, CORDE).

En este último caso, podría pensarse que nada más está yuxtapuesto al sintagma nominal que antecede, pero, dado que este tiene el rasgo [+persona], si le siguiera un indefinido, debería presentar la forma nadie más o ninguno más, o si lo que se quiere es negar la existencia de una cantidad mayor, no más, pero no nada más. $\mathrm{Su}$ empleo en este contexto muestra también su gramaticalización como adverbio de foco 'solamente', y esta gramaticalización lleva a que pueda anteponerse, anteposición tal vez favorecida por la existencia de la secuencia muy similar en forma y valor nada más que. Hallamos también ejemplos desde la segunda mitad del XVIII:

(50) Ofrecíte luego,/ cual siervo rendido,/ mi pecho encendido/ de tu dulce fuego,/ mas mi humilde ruego/ nada más abrojos/ de desdén y olvido/ en ti producía (Juan Meléndez Valdés, Poesías, 1775, CORDE).

\section{No más y Nada más en el español moderno}

A partir de este momento, una vez producida la gramaticalización de nada más (y nada más que), vemos que esta secuencia, en todos sus usos y valores, sigue aumentando su intensidad de empleo. En el siglo XIX, su uso se multiplica por cinco respecto al siglo anterior en los datos del CORDE, que recoge 2352 usos de nada más sobre un total de 43398647 palabras, lo que supone 54,2 apariciones por millón de palabras. Y por primera vez, las ocurrencias totales de nada más superan a las de no más. En el siglo XVIII, el CORDE recogía 383 casos de no más (y uno más con la grafía nomás), empleo 
casi 2,5 veces superior al de nada más; en el siglo XIX, hay 1628 ejemplos de nomás/no más en el CORDE, cifra claramente inferior a los 2352 casos de nada más. De todas formas, aunque el empleo de nada más crece en todas las áreas, tanto en el español europeo como en el americano, lo cierto es que el predominio de nada más en los ejemplos del XIX en el CORDE se debe a que la mayor parte de la documentación procede de textos españoles. Si comparamos el empleo de no más y nada más en España y América en el siglo XIX utilizando los datos del Corpus del Nuevo diccionario bistórico $(\mathrm{CDH})$, encontramos el siguiente reparto:

\begin{tabular}{|l|c|c|}
\hline & No más/nomás & Nada más \\
\hline España & $1036(34,8 \%)$ & $1940(65,2 \%)$ \\
\hline América & $720(55,8 \%)$ & $571(44,2 \%)$ \\
\hline
\end{tabular}

Vemos que, en el español de América, aunque también arraiga y alcanza difusión creciente nada más, no más sigue manteniéndose con fuerza, mientras que en España inicia un proceso de decadencia, que va a llevar, si no a la desaparición de esta secuencia, sí al progresivo desuso y final desaparición de no más como adverbio de exclusión. De hecho, si vemos los datos del CDH para el siglo XX, nada más sigue creciendo, pero de un modo moderado, pasando a ser un poco más frecuente que no más en Hispanoamérica, en tanto que sigue decreciendo de un modo muy acusado el uso de no más en el español europeo:

\begin{tabular}{|l|c|c|}
\hline & No más/nomás & Nada más \\
\hline España & $1525(19,1 \%)$ & $6454(80,9 \%)$ \\
\hline América & $4532(46,7 \%)$ & $5166(53,3 \%)$ \\
\hline
\end{tabular}

$\mathrm{Y}$, en los ejemplos de los primeros años del siglo XXI (hasta 2016) recogidos en el Corpus del Español del Siglo XXI (CORPES $X X I)$, sigue bajando la proporción de uso de no más en España, en tanto que se mantiene e, incluso, aumenta un poco respecto al siglo XX en Hispanoamérica: 


\begin{tabular}{|l|c|c|}
\hline & No más/nomás & Nada más \\
\hline España & $959(14,8 \%)$ & $5518(85,2 \%)$ \\
\hline América & $7769(48,5 \%)$ & $8247(51,5 \%)$ \\
\hline
\end{tabular}

Naturalmente, nada más, además de presentar usos como adverbio de foco, puede ser un sintagma nominal con una determinada función oracional: "no vio nada más”, "no sé nada más”, frecuentes en todas las áreas, y no más puede formar parte de una construcción comparativa con estimación numérica: “no más de diez minutos” o ser una negación que precede a un sintagma nominal encabezado por más en función adjetiva: "no más violencia”, construcciones normales también en España, pero estas notables diferencias de empleo entre España e Hispanoamérica, no cabe duda, están en relación con la desaparición de no más como adverbio de foco en España y su mantenimiento, junto a nada más, en Hispanoamérica. De este modo, es posible en el español hispanoamericano una construcción como "Sombras nada más", sintagma que se encuentra en el bolero Sombras del mexicano Javier Solís, o en el título de una conocida novela del nicaragüense Sergio Ramírez, pero, también, "sombras no más”, como vemos en el poema de la cubana Gertrudis Gómez de Avellaneda ${ }^{21}$ : "Si le osas contemplar quedarás ciego,/ Sombras no más hallando en sus fulgores” (Gertrudis Gómez de Avellaneda, Dios y el hombre, 1842, CORDE). En el español peninsular, desde el siglo XIX, no más como adverbio de foco de exclusión presenta un uso marginal, aunque aún puedan hallarse ejemplos residuales, y probablemente ya arcaizantes de esta variante, hasta el siglo XX.

(51) [L]as ráfagas luminosas que instantáneamente, en algunas ocasiones, cruzaban el espacio, poblaban el aire de terribles espectros y servían no más para dejar ver los abismos sin fin de la degradación humana (Antolín López Peláez, La vida de la Virgen, 1916, CORDE).

21 Aunque establecida en Madrid a partir de los 22 años, en 1826. 
Y no es seguro que en el español peninsular llegara a darse la completa gramaticalización y univerbación de nomás, con pérdida de tonicidad del adverbio de negación. La grafía unitaria nomás es frecuente en los textos hispanoamericanos del siglo XX y, según los datos de CORPES XXI, predominante en el siglo XXI ${ }^{22}$. La completa gramaticalización y univerbación de nomás también se manifiesta en la aparición de una forma de diminutivo, nomasito. Este hecho no es infrecuente en América, también con otros adverbios. El ejemplo más antiguo que localizo en el CORDE, de finales del XIX, es colombiano. También de Colombia procede otro ejemplo de 1885, que localizo a través de la búsqueda avanzada de Google libros ${ }^{23}$ :

- ¿Hace mucho que pasó por aquí?

-Nomasito. Y siguió tranquilo con su grata ocupación (Rivas 1885: 20).

(53) yo... un pobre diablo, un infeliz, que no puedo brindarle más que mi corazón..., más que mis lágrimas! ¡Por eso me voy, nomasito me alivie... ¡ a donde nunca más la vuelva a ver!... (Tomás Carrasquilla, Frutos de mi tierra, 1896, Colombia, CORDE),

y es actualmente de uso especialmente intenso en Centroamérica ${ }^{24}$.

Los pocos ejemplos españoles que recoge el CORPES XXI con la grafía nomás corresponden a citas de autores hispanoamericanos o a imitación consciente de variantes hispanoamericanas.

También, en el siglo XVIII, encontramos algunos usos de no más, sobre todo acompañando a adverbios y verbos, que parecen deslizarse hacia otros valores, como el de 'simplemente' o el meramente

22 El CDH recoge 2713 casos de no más y 1819 de nomás en textos hispanoamericanos del siglo XX. El CORPES XXI ofrece 3601 ejemplos de no más y 4168 de nomás en textos hispanoamericanos. Por supuesto, no todos los ejemplos de no más, aunque sí muchos, corresponden a usos como adverbio de foco.

23 Accesible en línea: https://books.google.es/advanced_book_search [Consultado el 30 de mayo de 2020].

24 El CE, en el subcorpus Web/dialects, recoge 30 ejemplos, la mayoría centroamericanos y con mucha frecuencia acompañando a adverbios de lugar, como aqui, abi, alli: 22, de Nicaragua; 4, de El Salvador; y 1, de Honduras, además de 2 de México. Señala, además, 2 ejemplos de España, pero, aparte de ser el mismo repetido, proceden del Diccionario panbispánico de dudas (DPD), donde se ejemplifica la forma nomasito con una cita de la chilena Marcela Serrano (Vida, 1995). 
enfático, a veces equivalente a 'mismo', 'precisamente'. Estos usos se documentan en España:

(54) Si todo cediera,/ Ahora no más,/ Sumiso al imperio/ De mi voluntad,/ Ahora, Pirene,/ Lanzárame allá (Francisco Sánchez Barbero, Poesías, c. 1800-1819 CORDE $)^{25}$,

pero con más intensidad en Hispanoamérica, a pesar de que el volumen de textos hispanoamericanos recogidos en esta época por el CORDE es menor que el de los textos españoles:

(55) Roguéles que siquiera me permitiesen levantar aquella cortina, para ver de allí no más (Catalina de Jesús Herrera, «Secretos entre el alma y Dios», Letras de la Audiencia de Quito (Periodo Jesuítico), 1675, Ecuador, CORDE),

ejemplo que quizá puede entenderse como contexto puente, contexto ambiguo que permite inferir un nuevo significado (Heine 2002). La idea de 'para ver solo desde allí', permite inferir 'desde allí y no desde otro sitio', ‘justamente desde allí, 'desde allí mismo’.

(56) Apéese no más (El amor de la estanciera, c. 1778, Argentina, CORDE).

Y se halla también el uso de así no más con el valor de 'regular'

CANCHO. ¿Coo le va, amigo Juancho?

JUANCHO. Así no más, bueno (El amor de la estanciera, c. 1778, Argentina, CORDE).

$\mathrm{Y}$ en el siglo XIX, mientras en Hispanoamérica crecen y se afianzan estos empleos de nomás, en España prácticamente desaparecen $^{26}$. Hemos buscado en $C D H$ los casos en que a no más

25 En el CORDE, se recoge un ejemplo anterior en que no más sigue a abora: "Espejo. ¡Fuego de Dios, y qué pico!/ Chica. Pues ahora no más empiezo;/ ya ustedes verán después/ que yo conozca el terreno" (Ramón de la Cruz, La niñería, 1768, CORDE), pero, a pesar de que no más, sin que, preferentemente sigue y no precede al elemento sobre el que incide, en este caso parece focalizar al verbo empiezo, no al adverbio abora.

26 Sobre los diversos usos de nomás en el español americano, además del focalizador ‘solamente', y su distribución geográfica, véase Kany (1945). Sobre el uso de nomás en 
(o nomás, grafía todavía poco frecuente en los textos del XIX) le precede un adverbio, y vemos ya un uso intenso de esta construcción en Hispanoamérica (144 ejemplos con las grafías no más y nomás ${ }^{27}$ ), frente a su práctica desaparición en España. El CDH solo recoge un ejemplo de Pereda, puesto en boca de un personaje que emplea diversos vulgarismos:

(58) [E]stábamos juegando al marro, y salí yo, y dipés toqué; y como él me pillaba, ya no me podía pillar, porque yo toqué... y dipés saqué un poquitin el pié... así, así no más ${ }^{28}$; y porque le saqué, dice que no toco, y me pilla (José María de Pereda, «Las tres infancias», Esbozos y rasguños, 1878, CDH).

Otro de Pardo Bazán, en que no más sigue a aquí, no incide realmente sobre el adverbio, sino sobre el complemento de finalidad que sigue:

(59) $[\mathrm{N}]$ osotros tenemos un café a la salida de la Plaza Mayor y venimos aquí no más a poner el ambigú (Emilia Pardo Bazán, Insolación, 1898, CDH).

Es cierto que en este contexto no se usa no más actualmente en España, pero sí puede utilizarse nada más en su lugar, en tanto que nada más no se introduce en los contextos en que sigue a un adverbio o incide enfáticamente sobre un imperativo como siga no más. También podemos encontrar, tanto en ejemplos españoles

Argentina, véase Vidal de Battini (1964: 185). Kornfeld (2014: 34) entiende algunos de estos usos argentinos como ejemplos de atenuador, elemento que se usa para mitigar el alcance de un acto de habla o suavizar un acto de habla. Esto podría aplicarse a su uso tras imperativo, pero difícilmente tras adverbio. Flores Treviño (2017) estudia nomás y nada más entre los marcadores de foco de exclusión que presentan función atenuante en el noreste de México.

27 En realidad, $C D H$ recupera 15 casos si se le pide que recupere adv. + nomás, y 404 ejemplos si se le pide adv. seguido de no más en el período 1801-1900, pero, en algunos casos, no más no incide sobre el adverbio precedente y, en otros, aparecen elementos que no son adverbios precediendo a no más, pero aparecen catalogados como tales en $C D H$, como y o si, o algunos casos tan sorprendentes como Ana.

28 Aunque esta es la puntuación que aparece desde la edición original, no sería imposible interpretar el ejemplo como “así, no más”, 'no [lo saqué] más'. 
como hispanoamericanos, la secuencia ya no más, pero en este caso no más no es un adverbio de foco, sino el adverbio de negación seguido de un pronombre o determinante indefinido. Cuando más es pronombre, en muchos casos se acerca contextualmente al valor de la exclamación basta ${ }^{29}$.

(60) Después dejó caer el puño sobre el brazo del sillón con tanta fuerza, que se estremeció ligeramente el piso. Parecía decir: - Ya no más, ya no más (Benito Pérez Galdós, La familia de León Roch, 1878, CDH).

De todas formas, aunque el uso de adverbio + no más/nomás se registra en los ejemplos del XIX en toda Hispanoamérica, e igualmente seguimos viéndolo en los del siglo XX y XXI consultados en $C D H$ y CORPES XXI, podemos observar que es un uso más intenso en los países del Cono Sur. En los ejemplos del $C D H$, es un uso especialmente frecuente en los que proceden de Argentina, frente a un uso mucho menor en México. En el español actual, los datos por países que ofrece el CE (Web/Dialects) de adverbio + nomás/no más muestran un uso especialmente frecuente en Paraguay, Uruguay, Argentina y Chile; un uso menor en México y Centroamérica; y, sobre todo, un uso aún más reducido en el área caribeña y Las Antillas. Si tenemos en cuenta solo los casos en que se usa la grafía unitaria nomás, destaca la frecuencia de uso en Paraguay (7,43 palabras por millón), Argentina (4,4 p.p.m.) y Uruguay (4,44 p.p.m.); si a estos sumamos los casos de la grafía no más, se unen a estos otros del cono Sur y del área andina, que superan o se quedan muy próximos a los 5 casos por millón de palabras: Paraguay (8,51 p.p.m.), Chile (6,83 p.p.m.), Perú (5,91 p.p.m.), Uruguay (5,57 p.p.m.), Argentina (5,5 p.p.m.), Bolivia (4,98 p.p.m.); más lejos

\footnotetext{
29 Aunque menos frecuente, también puede aparecer el adverbio de foco, univerbado y con acento de intensidad solo sobre la a, siguiendo a ya, con el valor de 'ahora mismo', 'enseguida', 'justo en un momento dado'. La utilización de la grafía nomás resulta útil para apuntar claramente a ese valor: "María: ¡En un ratito ya nomás chilla el tren, ya nomás baja la Marita, ya nomás camina hasta acá, ya nomás abre el portón, ya nomás me besa, ya nomás se pega el fuentonazo" (Bona, Gilda, Batir de alas, Argentina, CDH).
} 
quedan los resultados de Ecuador (3,09 p.p.m.). Un segundo bloque estaría constituido por México y los países centroamericanos: Nicaragua (4,23 p.p.m.), Guatemala (3,37 p.p.m.), México (3,07 p.p.m.), Costa Rica (3,01 p.p.m.), El Salvador (2,83 p.p.m.), Honduras (2,08 p.p.m.). Un tercer bloque lo constituirían los países caribeños de Sudamérica: Venezuela (2,1 p.p.m.), Colombia (2,01 p.p.m.) y, especialmente, los de las Antillas, que presentan índices de empleo en torno a un caso por millón de palabras o inferior: Cuba $(1,08$ p.p.m.), Puerto Rico (0,96 p.p.m.), República Dominicana (0,8 p.p.m.), similares a los de España (0,88 p.p.m.). Por supuesto, hay que tener en cuenta que algunos de los casos de no más no corresponden al adverbio de foco o al uso enfático, como de hecho sucede en la mayoría de los ejemplos de España (en otros se trata de citas de hablantes de otras zonas o textos de hablantes de otras áreas publicadas en medios españoles). Es frecuente la secuencia ya no más (1100 casos de los 2770 totales), en la que, como hemos visto, casi nunca es adverbio de foco no más, y a este tipo corresponden, por ejemplo, muchos de los casos que el CE recoge para México:

(61) Compras ropa cómoda Ya no más jeans ajustados o zapatos de memelas (10 formas de saber que ya no eres 'chavo' - Afmedios, $C E)$.

(62) [C]uando contesté su llamada me dijo que quería verme y que sentía mucha rabia que no estemos juntos, le dije que ya no más que podría hasta escucharlo por teléfono, pero verlo me da mucho miedo (Las Almas Gemelas - Cafeconcert-Relacionarse, $C E)$.

El bajo índice de empleo de nomás en las Antillas tal vez pueda deberse al mayor tiempo que estuvieron políticamente unidas a España.

Como consecuencia de la fijación de nomás en el valor de 'solamente', encontramos, también, la posibilidad de que le preceda el propio adverbio no, que es uno de los elementos que se han aglutinado para la constitución del nuevo adverbio de foco. Así, podemos hallar la secuencia no nomás 'no solamente', paralela a la secuencia 
no només, que se ha desarrollado en catalán también. De hecho, es de empleo muy frecuente, aunque algunos tratadistas no lo consideren correcto. Así, la Universitat Oberta de Catalunya, en su sección de dudas frecuentes, considera que debe evitarse no només y utilizarse no solament en estos $\operatorname{casos}^{30}$, en tanto que el portal lingüístic de la Corporació Catalana de Mitjans Audiovisuals de la Generalitat de Catalunya señala que "L'ús de l'adverbi només en la combinació no només és del tot lícit. No només era un gran professional, sinó també una gran persona", aunque también señala otras alternativas $^{31}$. Asimismo, es un uso especialmente característico del español de México (Kany 1945: 74) y, en menor medida, de Centroamérica. Puede entrar en correlación con sino en construcciones adversativas exclusivas. El primer ejemplo que recoge el CORDE es de Juan Rulfo, pero, en la búsqueda avanzada de Google Libros, pueden hallarse ejemplos desde finales del siglo XIX:

(63) Y no nomás de la justicia de Dios se olvida el Sr. Valle; también se olvida del...pudor (José Ferrel 1892: 132).

(64) [L]árgate a dar una vuelta por los Estados, pero no nomás en tus cochecitos Presidenciales, para que veas en qué estado se encuentra la agricultura (Proteo 1902: 142).

(65) [E]l médico vive y medra, y se la pasa no nomás pagado, sino mimado por esa gente (P. Lussa, Charla de sobremesa, en Informador, Guadalajara, 31 de julio de 1941, citado en Kany 1945: 74).

(66) Pero usté me nació. Y usté tenía que haberme encaminado, no nomás soltarme como caballo entre las milpas (Juan Rulfo, $E l$ llano en llamas, 1953, CORDE).

El CE (Web/Dialects) recoge ejemplos de no nomás en el español actual procedentes, en su mayoría, de México; otros que recoge de

\footnotetext{
30 Sobre esto, véase https://cv.uoc.edu/tren/trenacc/web/LLENGUA.GLOSSNOMEN/ glossari_entrades.detall?entrada=171 [Consultado el 30 de mayo de 2020].

31 Sobre esto, véase http://esadir.cat/entrades/fitxa/node/no_nomes_[Consultado el 30 de mayo de 2020].
} 
otras áreas corresponden generalmente a construcciones diferentes ${ }^{32}$, como el siguiente ejemplo chileno, en el que nomás, situado tras el adverbio de negación, viene a tener el valor de 'sencillamente':

(67) Hay que ser fuertes, decir que no nomás, negar se hasta el fin (8 cosas estúpidas que hacemos "estudiando", Juvenoide, CE).

La equivalencia que se observa generalmente entre el uso de no más y nada más hace que, en el español de México, se llegue a encontrar también la secuencia no nada más 'no solamente'.

(68) no nada más es una historia de terror es una historia también/ a ver/ de moral es una historia de enseñanza (Hablante: Loren Michan, estudiante, en Noticieros Televisa: Sin filtro: jóvenes $y$ religiones, 2013. Procedencia: Transcripción_y_codificación_ CORPES. Medio de difusión: Internet. Tipología: Tertulia, CORPES XXI).

Aunque este es el único caso que se registra en CORPES XXI, la construcción debe ser bastante frecuente en el habla actual de México. El CE (Web/Dialects) lo registra en México con una frecuencia relativamente alta: 577 ejemplos y 2,35 ocurrencias por millón de palabras, de hecho, muy superior a la de no nomás (33 ejemplos y 0,13 casos por millón de palabras); y, en el PRESEEA, se recogen tanto las secuencias no nomás como no nada más con el valor de 'no solo', siempre en conversaciones procedentes de México. Aunque no en todos los ejemplos en que aparecen estas secuencias en PRESEEA nos hallamos ante este valor, hay que hacer notar que con más frecuencia lo presenta no nada más. También, hay más ejemplos de no nada más en correlación con sino que de no nomás en correlación con sino. Concretamente, encontramos 15 ejemplos de no nada más

32 En el caso de los 3 ejemplos de no nomás que se recuperan etiquetados como españoles (no 4, como en principio aparece cuando se pide en gráfico la distribución por áreas), uno de ellos está en aragonés, en un texto bilingüe en el que la correspondencia castellana dice no solo; otro procede de un diario en línea chileno, véase www.lanacion. cl [Consultado el 30 de mayo de 2020]. El tercero es un comentario hecho por un participante, no sabemos de qué país, a un artículo publicado en esferapublica, véase http:// esferapublica.org/nfblog/57557 I [Consultado el 30 de mayo de 2020]. 
'no solo': 8 procedentes de conversaciones de Ciudad de México y 7 de Guadalajara; particularmente, en 11 ocasiones ( 6 en México y 5 en Guadalajara), en correlación con sino, por solo 4 de no nomás 'no solo' (1 de México y 3 de Guadalajara), de los cuales 1 (de Guadalajara) está en correlación con sino. Aunque en el registro escrito se halla menos que no nomás, la búsqueda avanzada en Google nos permite hallar al menos un ejemplo de principios del siglo XX:

(69) El C. Arellano: Pues si los diputados de la izquierda están tan convencidos de lo que digo, es claro que abogarán porque la Comisión retire el artículo a debate, lo que será la mejor prueba y no nada más palabras (Diario de los debates de la Cámara de Diputados del Congreso de los Estados Unidos Mexicanos 1917).

\section{Conclusiones}

A partir de construcciones comparativas del tipo ET NON MAGIS con elisión del segundo término, especialmente en la comparación de cantidad, se debió formar, en el latín tardío, una secuencia que adquiere el valor focal de exclusión de 'solamente' del tipo DUOS LIBRI ET NON MAGIS. En castellano y en otros romances, como el francés y el catalán, encontramos, desde los textos medievales más antiguos, las secuencias e/y no más, et non mais, e/i no més. En textos peninsulares anteriores al comienzo de la escritura romance, vemos con ese mismo valor la fórmula latina ET NON MAGIS. Una vez gramaticalizada la secuencia como adverbio de foco, se producirá la eliminación de la conjunción $y$, reduciéndose la secuencia a no más, pospuesta al elemento que focaliza. Debido a los orígenes de este marcador de foco, el elemento al que focaliza es, en principio, un sustantivo al que se pospone. Aunque documentada desde los primeros textos castellanos, e incluso en algún texto escrito en latín en el siglo XI, el marcador sin conjunción copulativa tiene una intensidad escasa de uso en la Edad Media. En el español clásico, crece en gran medida el uso de este marcador focal y, junto con ese crecimiento, se da también el de la forma sin conjunción (aunque y no más es también frecuente). A partir del siglo XV, y, 
sobre todo, del XVI, también comenzamos a encontrar la secuencia no...nada más delque (más frecuente con de, porque partimos de secuencias de carácter cuantitativo, y era ya lo más frecuente también en no más de) o nada más delque si la secuencia precede al verbo. En ella, nada funciona como refuerzo de la negación, forma enfática respecto a no...mas de/que. El siglo XVIII es decisivo en el desarrollo del adverbio de foco nada más. Por una parte, crece en gran medida el empleo de la construcción (no)...nada más del que; por otro lado, paralelamente a lo que sucede también con no más delque, la construcción con la preposición de decae rápidamente en favor de la construcción con que y, finalmente, comenzamos a encontrar y nada más o nada más pospuestos al elemento focalizado, a partir de una construcción con elipsis. En cuanto a su uso, supera la restricción originaria de acompañar a sustantivos, y comenzamos a encontrarlo, al menos desde la segunda mitad del XVIII, focalizando también a adjetivos y verbos. Ya consolidado en esta función, puede rebasar la inicial limitación de posición y anteponerse al elemento focalizado, aunque es empleo menos frecuente.

También, a partir del XVIII, y acentuándose enormemente en el XIX y en el XX, vemos una diferente evolución en el español europeo y en el americano. Es cierto que el adverbio de foco nada más (y también las construcciones comparativas con valor focalizador de 'solamente') crece en todas las áreas hispanohablantes, hasta igualar (e, incluso, superar) el uso de no más/nomás, pero, mientras este adverbio de foco se mantiene con fuerza junto a nada más en Hispanoamérica, en España decae rápidamente hasta sentirse, primero, como elemento arcaizante y desaparecer totalmente del uso después. En Hispanoamérica, por el contrario, sigue teniendo un uso intenso y llega a desarrollar nuevos valores, no siempre coincidentes en su uso o en su intensidad de empleo en todas las áreas, que le permiten acompañar a un adverbio de lugar, tiempo o modo, con valores semejantes a los de 'mismo' (abi nomás) o 'justamente', 'precisamente'. Asimismo, puede acompañar a un verbo, con mucha frecuencia en imperativo, añadiendo simplemente un valor enfático, usos que no llegaron a desarrollarse en España y que tampoco ha desarrollado nada más. 
Al estudiar la creación y desarrollo de estos dos adverbios de foco, hemos visto cómo el surgimiento de nada más, que muestra paralelismos con el de nomás, nos permite ver claramente los distintos pasos de su formación: surgimiento de una construcción comparativa que rutiniza su uso con un valor focalizador de exclusión, y creación de una construcción pospuesta, coordinada o yuxtapuesta (y nada más, nada más) en la que se da un fenómeno de elipsis (estos pasos ya consumados en el caso de no más desde los textos castellanos primitivos). El crecimiento del uso y la gramaticalización de la construcción nada más constituyen un proceso paralelo al que en el español medieval y clásico se había producido con no más, y, a partir de la equiparación de nada más a nomás como marcador de foco, podemos ver distintas preferencias y procesos evolutivos en los distintos territorios hispanohablantes.

\section{Referencias bibliográficas}

Bassols de Climent, Mariano

1981 Sintaxis latina. Vol. I y II. Madrid: CSIC.

$B D H=$ Biblioteca Nacional de EsPaña

s/f Biblioteca Digital Hispánica $(B D H)$. Consultado: mayo-julio de 2018. <http://www.bne.es/es/Catalogos/BibliotecaDigitalHispanica/Inicio/index.html>.

BOURCIEZ, Édouard

1946 Éléments de linguistique romane. París: Klincksieck.

$C D H=$ InSTITUTO DE INVESTIGACIÓN RAFAeL LAPESA DE LA REAL Academia Española

s/f Corpus del Nuevo diccionario bistórico (CDH). Consultado: junio de 2018 http://web.frl.es/CNDHE

CE (Web, Dialects $)=$ Davies, Mark

s/f Corpus del Español (CE). Consultado: mayo-julio de 2018 $<$ https://www.corpusdelespanol.org/web-dial/>.

$C I C A=$ Torruella, Joan (Dir.), Manuel Pérez Saldanya y Josep MarTines $\mathrm{s} / \mathrm{f} \quad$ Corpus Informatitzat del Català Antic (CICA). Consultado: junio de 2018. <http://cica.cat $>$. 
CORDE $=$ REAL ACADEMIA EsPañolA

s/f Corpus Diacrónico del Español (CORDE). Consultado: mayojulio de 2018. <http://corpus.rae.es/cordenet.html>

CORPES $X X I=$ REAL ACADEMIa EsPañola

$\mathrm{s} / \mathrm{f} \quad$ Corpus del Español del Siglo XXI (CORPES XXI). Consultado: junio de 2018. <http://web.frl.es/CORPES/view/ inicioExterno.view $>$.

Covarrubias, Sebastián de

2001 Suplemento al Tesoro de la Lengua Española Castellana. Eds., Georgina Dopico y Jacques Lezra. Madrid: Polifemo.

Diario de los Debates de la Cámara de Diputados del Congreso de los Estados Unidos MeXicanos

1917 Sesión de la cámara de diputados celebrada el 7 de diciembre de 1917. Período ordinario. Legislatura XXVII. II, 78. México, sábado 8 de diciembre de 1917. Consultado: julio de 2018. <http://cronica.diputados.gob.mx/DDebates/27/2do/ Ord/19171208.html>.

Espinosa Elorza, Rosa María

2014 "Adverbios de cantidad, foco, polaridad y modalidad". En Sintaxis histórica de la lengua española. Tercera parte: Preposiciones, adverbios y conjunciones. Relaciones interoracionales. Vol. 1. Ed., Concepción Company Company (Dir.). México: UNAM/FCE, 939-115.

FERrel, José

1892 Los de la mutua de los elogios. Mazatlán (México): Imprenta de Retes. Consultado: abril de 2020. <https://archive.org/ stream/losdelamutuadee00ferrgoog/losdelamutuadee00ferrgoog_djvu.txt>.

Flores TreviÑo, Marcela

2017 "La atenuación y los marcadores de foco de exclusión en los corpus: PRESEEA-Mty / AMERESCO-Méx.Mty”. Normas. 7, 1, 19-32.

García PÉrez, Rafael

2013 "La evolución de los adverbios de foco en español: adverbios focalizadores de exclusión, inclusión y aproximación". En Los adverbios con función discursiva. Procesos de formación 
y evolución. Ed., Pilar Garcés Gómez. Madrid/Frankfurt am Main: Iberoamericana/Vervuert, 317-387.

GĂZDARU, Demetrio

1949 "Español no más y rumano númaĭ en su desarrollo paralelo". Filología. I, 2, 23-42.

HeIne, Bernd

2002 "On the role of contexts in grammaticalization". En New Reflections on Grammaticalization. Eds., Ilse Wischer y Gabriele Diewald. Amsterdam: Benjamins, 83-101. https:// doi.org/10.1075/tsl.49.08hei

Herrero Ruiz de Loizaga, Francisco Javier

2005 Sintaxis histórica de la oración compuesta en español. Madrid: Gredos.

2016 "La elisión en la formación de conjunciones y marcadores discursivos”. En Semántica latina y románica. Unidades de significado conceptual y procedimental. Eds., Benjamín García Hernández y María Azucena Penas Ibáñez. Berna: Peter Lang, 351-386.

Iglesias Recuero, Silvia

2014 "Oraciones adversativas". En Sintaxis histórica de la lengua española. Tercera parte: Preposiciones, adverbios y conjunciones. Relaciones interoracionales. Vol. 2. Ed., Concepción Company Company. México: UNAM/FCE, 2519-2669.

KANY, Charles E.

1945 “American Spanish no más”. Hispanic Review. XIII, 1, 72-79. https://doi.org/10.2307/469643

KoRnFeld, Laura Malena

2014 "Dale nomás... Misterios y revelaciones de un clásico rioplatense”. Filología, LXVI, 333-355.

LLORENS, Eduardo L.

1929 La negación en español antiguo con referencias a otros idiomas. Madrid: Consejo Superior de Investigaciones Científicas.

Melander, Johan

1920 “L'origine de l'espagnol «no más» au sens de «seulement»". Studier i Modern Sprakvetenskap. VII, 77-84. 
Moignet, Gérard

1973 Les signes d'exception dans l'bistoire du français. Ginebra: Droz.

Moreto, Agustín

1675 Entremés del ayo, en Autos sacramentales y al nacimiento de Christo [...] recogidos de los maiores ingenios de España. Madrid: por Antonio Francisco de Zafra, a costa de Iuan Fernandez, mercader de libros.

NGLE = Real Academia Española /Asociación de Academias de la LENGUA EsPaÑola

2009 Nueva Gramática de la Lengua Española (NGLE). Madrid: Espasa Libros.

PRESEEA = Moreno Fernandez, Francisco (coord.)

(2014-) Corpus del Proyecto para el estudio sociolinguistico del espanol de Espana y de America. Alcala de Henares: Universidad de Alcala. Consultado: junio de 2018. <http://preseea. linguas.net>

Proteo

1902

"Eslabonazos. Siluetas". El Agricultor Mexicano. 13, 6, 138142. Consultado: julio de 2018. <http://www.hndm.unam. $\mathrm{mx} /$ consulta/publicacion/visualizar/558075bd7d1e63c9fea1a0 fo ?intPagina $=22 \&$ tipo $=$ publicacion $\&$ anio $=1902 \&$ mes $=06 \& \mathrm{di}$ $\mathrm{a}=01 \&$ but $\operatorname{Ir}=\operatorname{Ir}>$

Real Academia Española

1741 Orthographia. Madrid: Imprenta de la Real Academia Española.

RiCHTER, Elise

1908 "Zur Geschichte der Indeklinabilien”. Zeitschrift für romanische Philologie. XXXII, 656-677.

Rivas, Medardo

1885 Viajes por Colombia, Francia, Inglaterra y Alemania. Vol. 2. Bogotá: Imprenta Fernando Pontón. Consultado: julio de 2018. $<$ https://books.google.es/books?id=2_TSdkQJA9kC\&q=nomasito\&dq=nomasito\&hl=es\&sa $=X \& v e d=0 a h U K E w j a-$ 84j4oPjpAhVP4YUKHf6GA9w4ChDoAQhWMAY> 
Romero Cambrón, Ángeles

1998 Historia sintáctica de las estructuras comparativas de desigualdad. Cuenca: Ediciones de la Universidad de Castilla-La Mancha.

SANTiago, Ramón

1998 "Apuntes para la historia de la puntuación en los siglos XVI y XVII". En Estudios de grafemática en el dominio hispano. Eds., José Manuel Blecua, Juan Gutiérrez y Lidia Sala. Salamanca: Ediciones Universidad de Salamanca/Instituto Caro y Cuervo.

WEIGERT, L.

1907 Untersuchungen zur spanischen Syntax auf Grund der Werke des Cervantes. Berlín: Meyer \& Müller.

VidAl de BATtini, Berta

1964 El español de la Argentina. Buenos Aires: Consejo Nacional de Educación.

Recepción: 21/08/2019

Aceptación: 29/11/2019 